\title{
Background Radiation Survey of the Radiological/Nuclear Countermeasures Test and Evaluation Center
}

\author{
Colin Okada \\ Senior Scientist \\ Remote Sensing Laboratory \\ National Security Technologies, LLC
}

Survey Date:

June 15, 2009

This document is UNCLASSIFIED

\author{
Reviewed by \\ Timothy Rearich \\ Derivative Classifier
}




\section{DISCLAIMER}

This report was prepared as an account of work sponsored by an agency of the U.S. Government. Neither the U.S. Government nor any agency thereof, nor any of their employees, nor any of their contractors, subcontractors or their employees, makes any warranty or representation, express or implied, or assumes any legal liability or responsibility for the accuracy, completeness, or usefulness of any information, apparatus, product, or process disclosed, or represents that its use would not infringe privately owned rights. Reference herein to any specific commercial product, process, or service by trade name, trademark, manufacturer, or otherwise, does not necessarily constitute or imply its endorsement, recommendation, or favoring by the U.S.

Government or any agency thereof. The views and opinions of authors expressed herein do not necessarily state or reflect those of the U.S. Government or any agency thereof. 


\section{Introduction}

In preparation for operations at the Radiological/Nuclear Countermeasures Test and Evaluation Complex (Rad/NucCTEC), the Department of Homeland Security Domestic Nuclear Detection Office (DHS/DNDO) requested that personnel from the Remote Sensing Laboratory (RSL) conduct a survey of the present radiological conditions at the facility. The measurements consist of the exposure rate from a high-pressure ion chamber (HPIC), high-resolution spectra from a high-purity germanium (HPGe) system in an in situ configuration, and low-resolution spectra from a sodium iodide (NaI) detector in a radiation detection backpack. Measurements with these systems were collected at discrete locations within the facility. Measurements were also collected by carrying the VECTOR backpack throughout the complex to generate a map of the entire area. The area was also to be surveyed with the Kiwi (an array of eight-2" $\times 4$ " $\times 16$ " $\mathrm{NaI}$ detectors) from the Aerial Measuring Systems; however, conflicts with test preparation activities at the site prevented this from being accomplished.

\section{Measurements}

Measurements were collected at the fixed locations on June 9-10, 2009. Measurements were performed with the VECTOR backpacks on June 11, 2009.

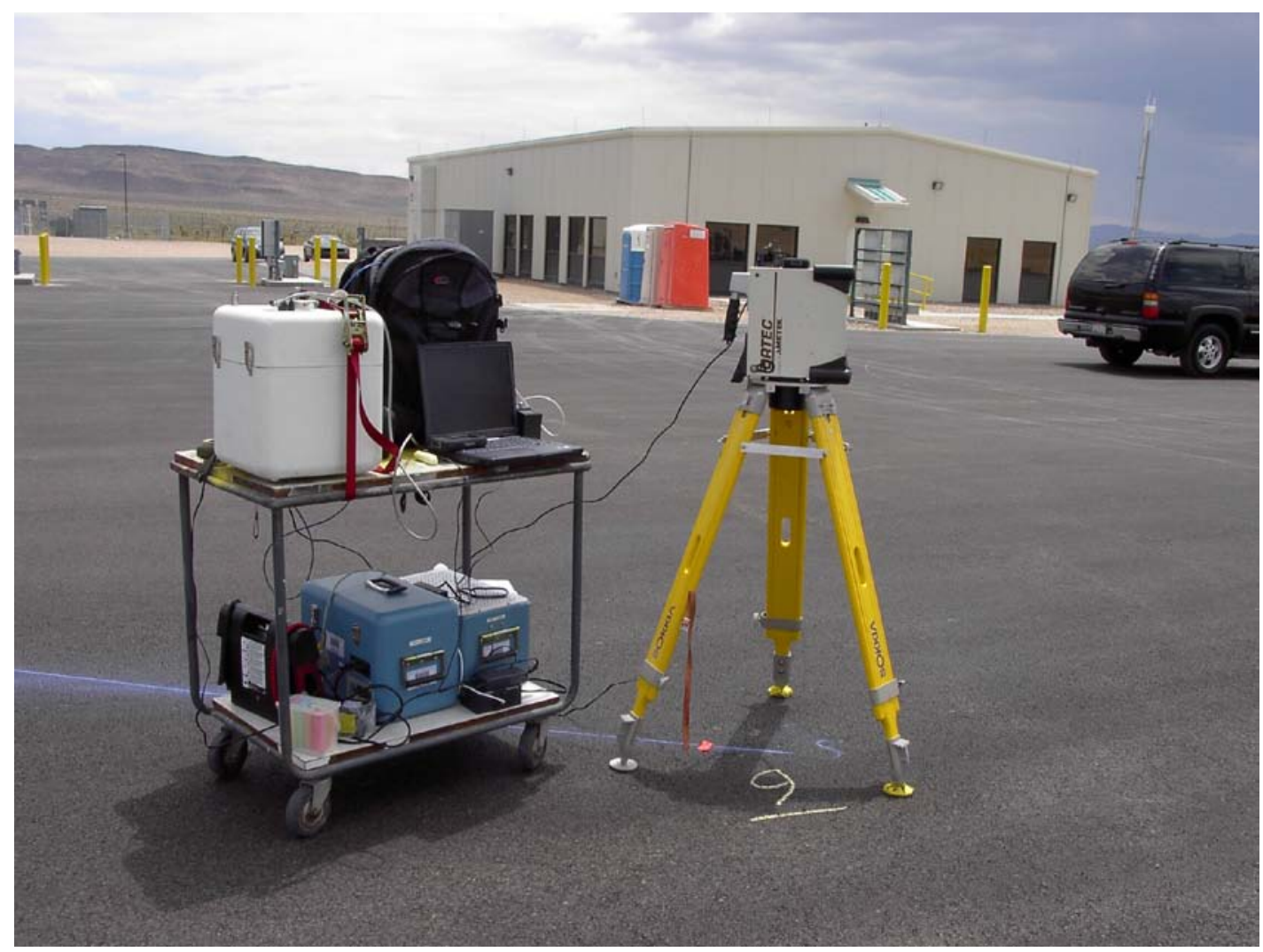

Figure 1: Setup for performing the static measurements. The HPIC and VECTOR are on top of the cart while the HPGe is on the tripod. Batteries on the bottom of the cart were used to power the various systems throughout the day. 
The positions for the discrete locations were recorded by collecting the coordinates reported from the GPS receiver contained within a ruggedized PDA which was used to interact with the radiation backpack. When the instruments had a clear view of the sky, the GPS coordinates were fluctuating at the 0.001' level (precision of approximately 6 feet). Because all of the measurements at the fixed locations were performed simultaneously, the accuracy of the position information is no better than 10 feet.

The exposure rate measurements were collected with an RSS-131 from GE/ReuterStokes. The RSS-131 is a 10"-diameter chamber filled with argon gas at a pressure of 25 atmospheres. Gamma-rays passing through the argon gas produce ions which provide a measure of the exposure rate. The interface to the RSS-131 was through a numerical display on a laptop computer. The measurements were performed by allowing the system to adjust to each new location before the exposure rate was recorded.

A VECTOR backpack was used to produce a gross count rate survey of the area and to collect mid-resolution NaI spectra. The VECTOR has a 2" × 2 ” $\times 8$ ” NaI detector for gamma-ray detection and spectrum capture. The system is usually used in a mode where it is writing the gamma-ray spectra and GPS location second-by-second to internal data storage. This normal mode was used for the area survey where two backpacks were pushed or carried at a walking pace, in a methodical fashion, throughout the area. For the spectra collected at the discrete locations, the one-second spectra were transmitted to a PDA where they were summed to produce a spectrum integrated over several minutes. The detector in the VECTOR was not gain stabilized, thus the energy calibration varies for the collected spectra. This can be seen by the comparison shown in Figure 2.

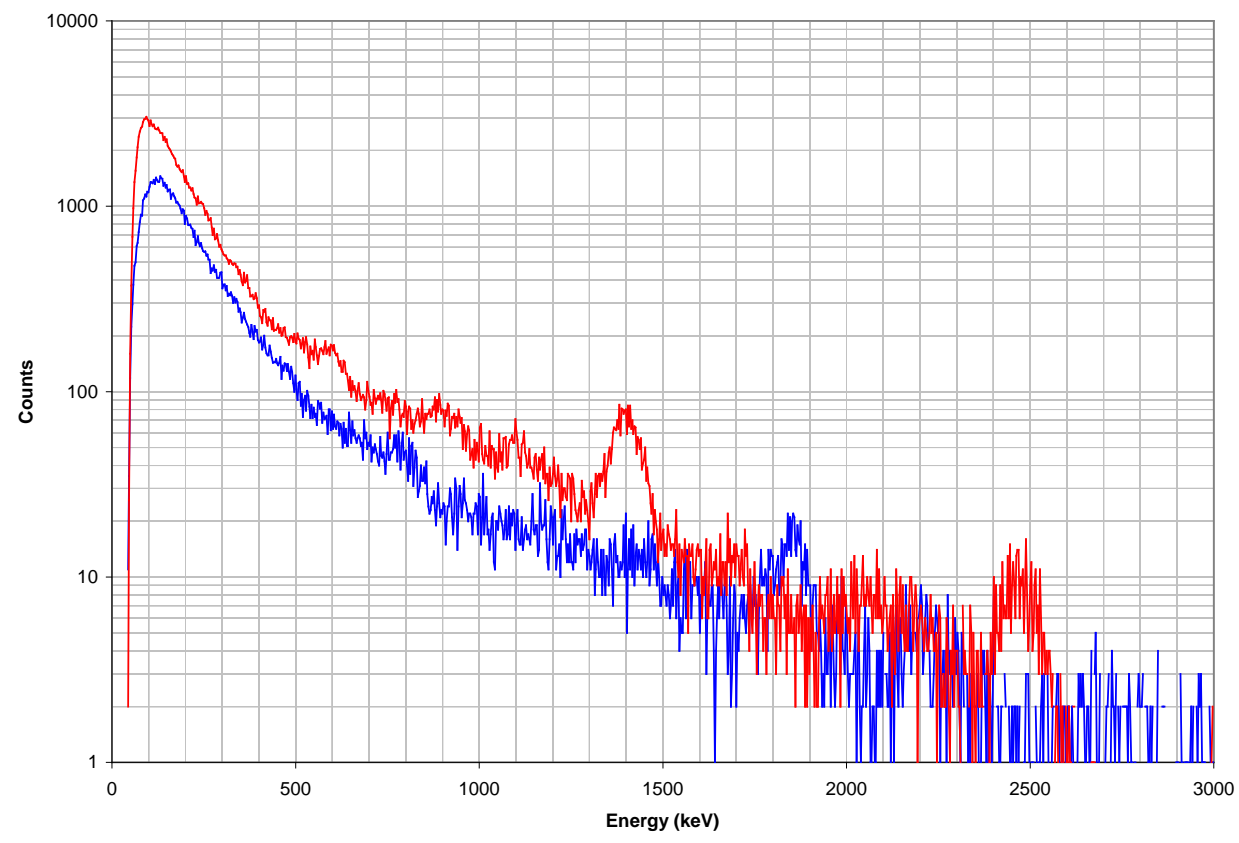

Figure 2: Illustration of the gain changes seen in the backpack detector. The spectrum in red (Location 26) shows the $40 \mathrm{~K}$ peak around $1400 \mathrm{keV}$, while the blue spectrum (Location 3 ) shows ${ }^{40} \mathrm{~K}$ around $1870 \mathrm{keV}$. 
The HPGe measurements were performed with an ORTEC Detective-EX100 (Serial Number 7464039) in an in situ configuration (i.e., the detector was on a tripod, facing toward the ground, with the face of the end cap 1 meter above the ground). This unit has an efficiency of $43.9 \%$ relative to a 3" $\times 3$ " NaI detector. The angular response and efficiency, as a function of energy for this system, were measured with ${ }^{241} \mathrm{Am},{ }^{152} \mathrm{Eu}$, and ${ }^{228}$ Th sources in April 2009. The angular efficiency, as a function of energy, was translated into a conversion to activity uniformly mixed in the soil for the in situ geometry. The coefficients for the conversion are given in Table 1.

Table 1: Coefficients for converting counts from in situ HPGe measurements to activity in the soil. The count rate in the spectrum peaks are corrected by the expected yield per decay and multiplied by the efficiency derived from this table to get $\mathrm{pCi} / \mathrm{g}$.

\begin{tabular}{|l|l|}
\hline Energy $(\mathrm{keV})$ & Efficiency $((\mathrm{pCi} / \mathrm{g}) / \mathrm{cps})$ \\
\hline 45 & $1.7056 \mathrm{E}+1$ \\
\hline 60 & $3.4228 \mathrm{E}+0$ \\
\hline 100 & $7.8275 \mathrm{E}-1$ \\
\hline 200 & $4.6472 \mathrm{E}-1$ \\
\hline 300 & $4.6675 \mathrm{E}-1$ \\
\hline 500 & $5.4242 \mathrm{E}-1$ \\
\hline 661 & $6.0197 \mathrm{E}-1$ \\
\hline 900 & $6.2384 \mathrm{E}-1$ \\
\hline 1000 & $6.3921 \mathrm{E}-1$ \\
\hline 1500 & $7.3007 \mathrm{E}-1$ \\
\hline 2000 & $7.9035 \mathrm{E}-1$ \\
\hline 2614 & $8.6326 \mathrm{E}-1$ \\
\hline
\end{tabular}

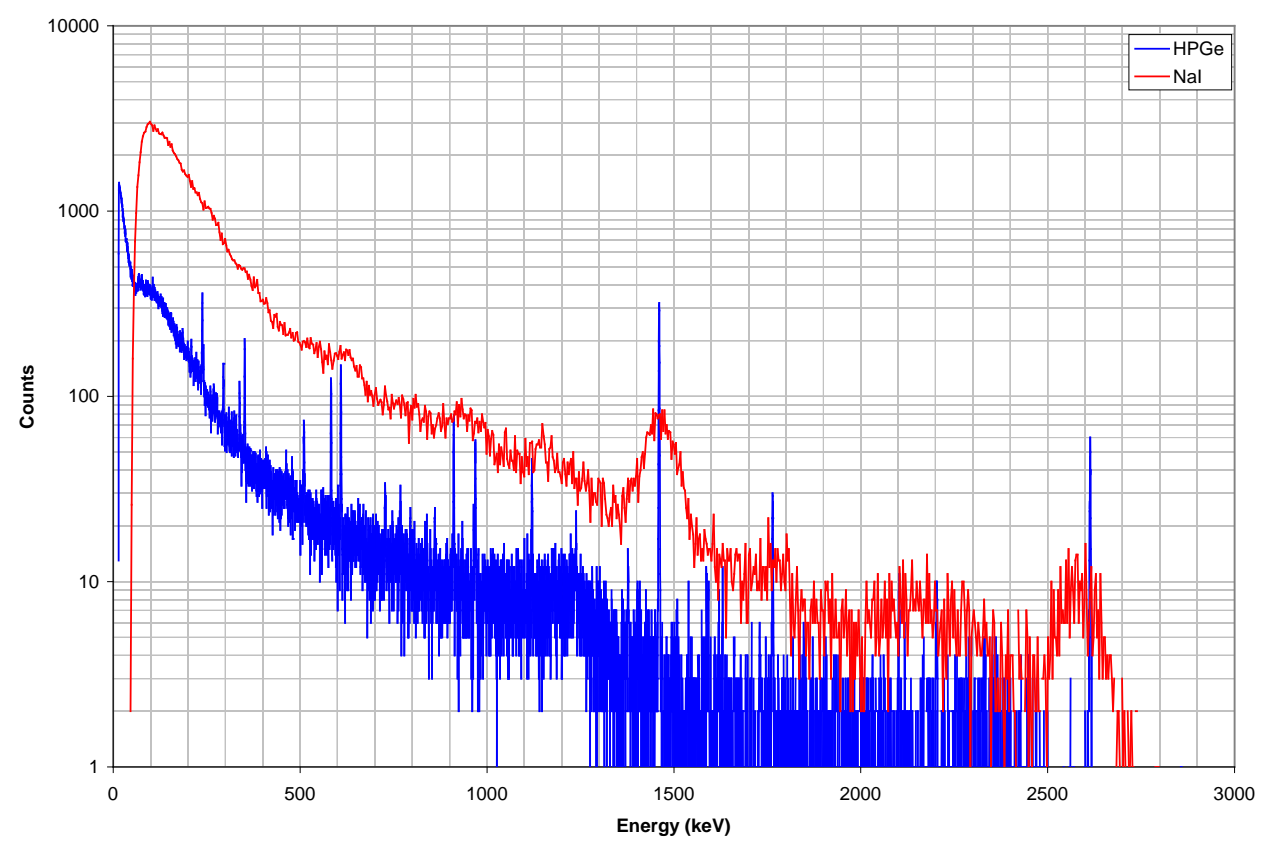

Figure 3: Comparison of spectra collected with the NaI detector in the VECTOR backpack and the in situ HPGe detector at Location 26. The energy calibration of the NaI spectrum has been corrected for this plot. 


\section{Results}

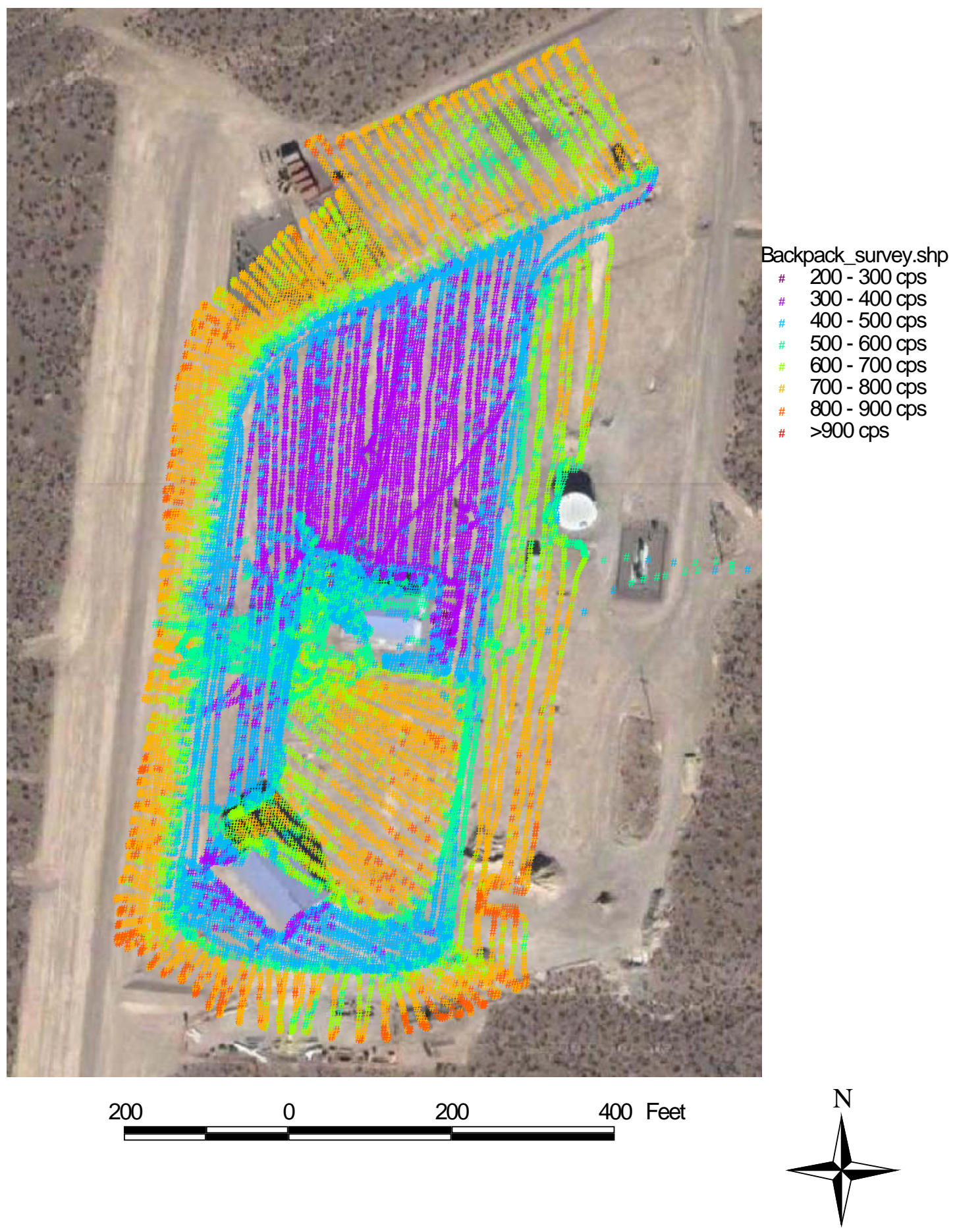

Figure 4: Survey of the Rad/NucCTEC facility as performed with the VECTOR backpacks. Only the gross count rate from the NaI detector in the backpack is plotted. The paved areas show a lower background than the unpaved areas. The image under the data was taken prior to laying down the asphalt in the complex. 
Table 2: Locations and exposure rates of the static measurements. The filenames for the NaI spectra collected with the VECTOR backpack are also listed. The GPS information for the measurements collected in the Active Interrogation Building is suspect, so they have been highlighted.

\begin{tabular}{|c|c|c|c|c|}
\hline Location & Latitude & Longitude & $\begin{array}{r}\text { Exposure Rate } \\
(\mu \mathrm{R} / \mathrm{hr}) \\
\end{array}$ & VECTOR filename \\
\hline 1 & $36^{\circ} 53.4137$ & $116^{\circ} 1.8375$ & 8.5 & LV_06092009_1627_XX.dat \\
\hline 2 & $36^{\circ} 53.4441$ & $116^{\circ} 1.8361$ & 8.5 & LV_06092009_1648_XX.dat \\
\hline 3 & $36^{\circ} 53.4743$ & $116^{\circ} 1.8283$ & 8.2 & LV_06092009_1708_XX.dat \\
\hline 4 & $36^{\circ} 53.4824$ & $116^{\circ} 1.8338$ & 8.3 & LV_06092009_1728_XX.dat \\
\hline 5 & $36^{\circ} 53.4858$ & $116^{\circ} 1.8393$ & 8.1 & LV_06092009_1744_XX.dat \\
\hline 6 & $36^{\circ} 53.4604$ & $116^{\circ} 1.864$ & 7.6 & LV_06092009_1807_XX.dat \\
\hline 7 & $36^{\circ} 53.4686$ & $116^{\circ} 1.8764$ & 8.2 & LV_06092009_1821_XX.dat \\
\hline 8 & $36^{\circ} 53.4334$ & $116^{\circ} 1.8906$ & 8.5 & LV_06092009_1839_XX.dat \\
\hline 9 & $36^{\circ} 53.4322$ & $116^{\circ} 1.8851$ & 8.3 & LV_06092009_1858_XX.dat \\
\hline 10 & $36^{\circ} 53.4299$ & $116^{\circ} 1.8924$ & 8.5 & LV_06092009_1915_XX.dat \\
\hline 11 & $36^{\circ} 53.4265$ & $116^{\circ} 1.8814$ & 8.8 & LV_06092009_1932_XX.dat \\
\hline 12 & $36^{\circ} 53.4464$ & $116^{\circ} 1.8654$ & 8.1 & LV_06092009_1951_XX.dat \\
\hline 13 & $36^{\circ} 53.4332$ & $116^{\circ} 1.8484$ & 8.5 & LV_06092009_2010_XX.dat \\
\hline 14 & $36^{\circ} 53.3949$ & $116^{\circ} 1.8947$ & 8.4 & LV_06092009_2028_XX.dat \\
\hline 15 & $36^{\circ} 53.3595$ & $116^{\circ} 1.9038$ & 10.9 & LV_06092009_2106_XX.dat \\
\hline 16 & $36^{\circ} 53.3562$ & $116^{\circ} 1.8791$ & 8.6 & LV_06092009_2125_XX.dat \\
\hline 17 & $36^{\circ} 53.3615$ & $116^{\circ} 1.8855$ & 8.1 & LV_06092009_2143_XX.dat \\
\hline 18 & $36^{\circ} 53.3656$ & $116^{\circ} 1.8956$ & 9.1 & LV_06102009_1554_XX.dat \\
\hline 19 & $36^{\circ} 53.3581$ & $116^{\circ} 1.8965$ & 8.8 & LV_06102009_1614_XX.dat \\
\hline 20 & $36^{\circ} 53.3545$ & $116^{\circ} 1.913$ & 10.1 & LV_06102009_1631_XX.dat \\
\hline 21 & $36^{\circ} 53.3858$ & $116^{\circ} 1.9011$ & 11.1 & LV_06102009_1664_XX.dat \\
\hline 22 & $36^{\circ} 53.3297$ & $116^{\circ} 2.0018$ & 10.7 & LV_06102009_1708_XX.dat \\
\hline 23 & $36^{\circ} 53.3855$ & $116^{\circ} 1.8434$ & 10 & LV_06102009_1725_XX.dat \\
\hline 24 & $36^{\circ} 53.3544$ & $116^{\circ} 1.848$ & 9.2 & LV_06102009_1745_XX.dat \\
\hline 25 & $36^{\circ} 53.3853$ & $116^{\circ} 1.8425$ & 9.2 & LV_06102009_1803_XX.dat \\
\hline 26 & $36^{\circ} 53.3881$ & $116^{\circ} 1.8562$ & 13.0 & LV_06102009_1823_XX.dat \\
\hline 27 & $36^{\circ} 53.4588$ & $116^{\circ} 1.8443$ & 7.5 & LV_06102009_1844_XX.dat \\
\hline 28 & $36^{\circ} 53.5025$ & $116^{\circ} 1.8306$ & 12.5 & LV_06102009_1925_XX.dat \\
\hline 29 & $36^{\circ} 53.475$ & $116^{\circ} 1.8878$ & 13.2 & LV_06102009_1945_XX.dat \\
\hline 30 & $36^{\circ} 53.4158$ & $116^{\circ} 1.9016$ & 12.8 & LV_06102009_2004_XX.dat \\
\hline 31 & $36^{\circ} 53.3631$ & $116^{\circ} 1.9107$ & 12.4 & LV_06102009_2023_XX.dat \\
\hline 32 & $36^{\circ} 53.3395$ & $116^{\circ} 1.8663$ & 10.3 & LV_06102009_2042_XX.dat \\
\hline 33 & $36^{\circ} 53.3752$ & $116^{\circ} 1.8343$ & 12.4 & LV_06102009_2111_XX.dat \\
\hline 34 & $36^{\circ} 53.4265$ & $116^{\circ} 1.8306$ & 12.3 & LV_06102009_2130_XX.dat \\
\hline 35 & $36^{\circ} 53.4844$ & $116^{\circ} 1.8192$ & 12.0 & LV_06102009_2149_XX.dat \\
\hline
\end{tabular}




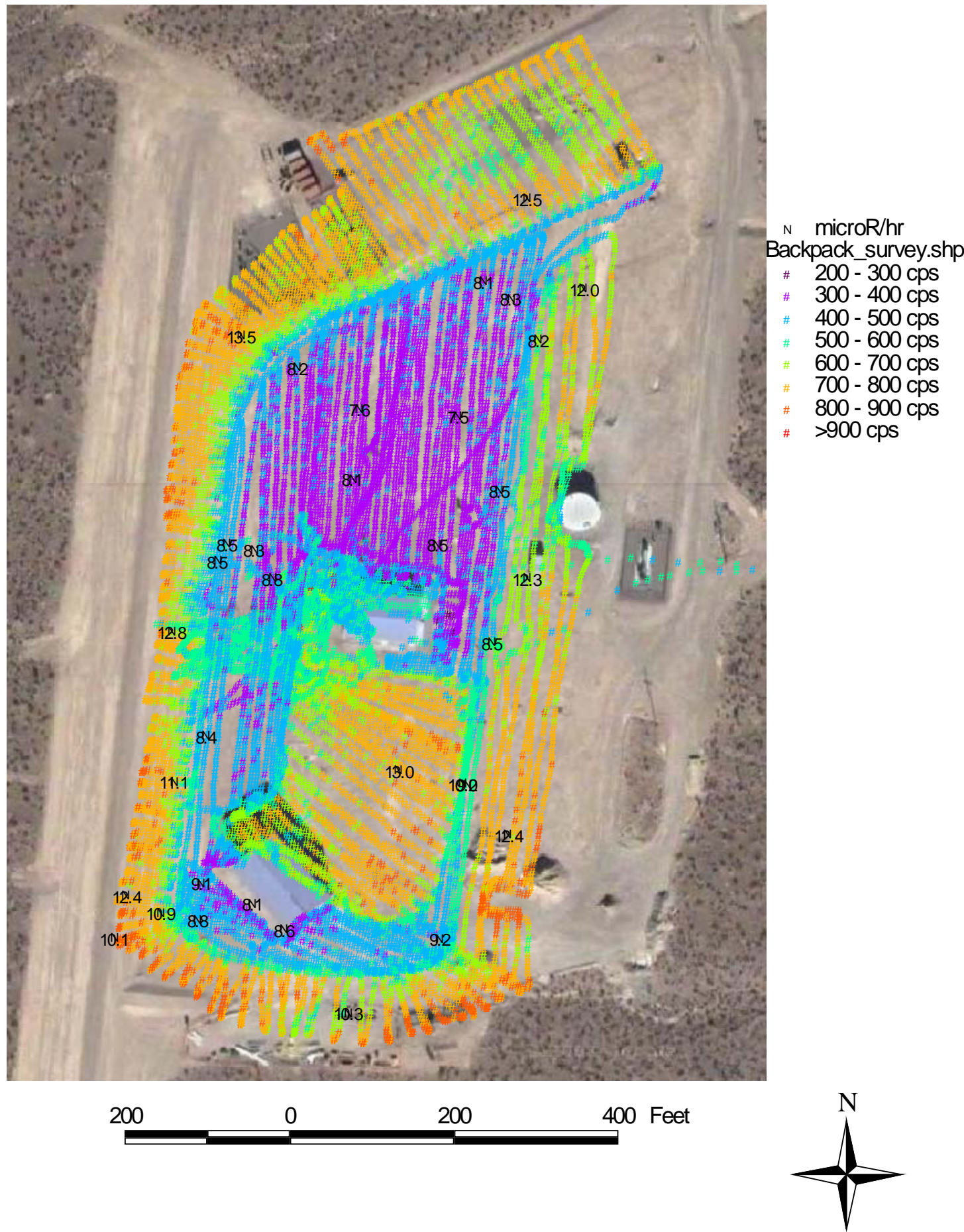

Figure 5: The measurements from the high-pressure ion chamber are shown on top of the backpack survey. The data shows good correlation between the HPIC and backpack. The measurements inside the Active Interrogation Building were excluded. 
Background Radiation Survey of the Radiological/Nuclear Countermeasures Test and Evaluation Center

Table 3: Results from the HPGe measurements. The areas of the peaks in the spectra were calculated, corrected by the yield per decay of the parent isotope, and multiplied by the efficiency of the detector for a source uniformly distributed in the soil. Whenever possible, the results from multiple peaks were combined to produce a weighted average activity concentration. The GPS information for the measurements collected in the Active Interrogation Building is suspect, so they have been highlighted.

\begin{tabular}{|c|c|c|c|c|c|c|}
\hline Location & Latitude & Longitude & HPGe filename & Ra-226 pCi/g & Th-232 pCi/g & $\mathrm{K}-40 \mathrm{pCi} / \mathrm{g}$ \\
\hline 1 & 36.890228 & -116.030625 & 090609_01.Spc & $0.567 \pm 0.024$ & $0.239 \pm 0.017$ & $3.725 \pm 0.17$ \\
\hline 2 & 36.890735 & -116.030602 & 090609_02.Spc & $0.544 \pm 0.024$ & $0.22 \pm 0.017$ & $3.435 \pm 0.165$ \\
\hline 3 & 36.891238 & -116.030472 & 090609_03.Spc & $0.545 \pm 0.023$ & $0.187 \pm 0.015$ & $2.868 \pm 0.15$ \\
\hline 4 & 36.891373 & -116.030563 & 090609_04.Spc & $0.553 \pm 0.023$ & $0.115 \pm 0.013$ & $2.586 \pm 0.143$ \\
\hline 5 & 36.891430 & -116.030655 & 090609_05.Spc & $0.499 \pm 0.023$ & $0.131 \pm 0.013$ & $2.873 \pm 0.152$ \\
\hline 6 & 36.891007 & -116.031067 & 090609_06.Spc & $0.549 \pm 0.023$ & $0.129 \pm 0.015$ & $2.293 \pm 0.133$ \\
\hline 7 & 36.891143 & -116.031273 & 090609_07.Spc & $0.495 \pm 0.022$ & $0.153 \pm 0.015$ & $2.787 \pm 0.149$ \\
\hline 8 & 36.890557 & -116.031510 & 090609_08.Spc & $0.594 \pm 0.025$ & $0.282 \pm 0.02$ & $4.398 \pm 0.184$ \\
\hline 9 & 36.890537 & -116.031418 & 090609_09.Spc & $0.598 \pm 0.024$ & $0.182 \pm 0.015$ & $2.901 \pm 0.151$ \\
\hline 10 & 36.890498 & -116.031540 & 090609_10.Spc & $0.585 \pm 0.024$ & $0.235 \pm 0.017$ & $3.238 \pm 0.159$ \\
\hline 11 & 36.890442 & -116.031357 & 090609_11.Spc & $0.591 \pm 0.024$ & $0.193 \pm 0.016$ & $2.568 \pm 0.143$ \\
\hline 12 & 36.890773 & -116.031090 & 090609_12.Spc & $0.572 \pm 0.024$ & $0.13 \pm 0.016$ & $2.504 \pm 0.14$ \\
\hline 13 & 36.890553 & -116.030807 & 090609_13.Spc & $0.528 \pm 0.022$ & $0.15 \pm 0.016$ & $2.402 \pm 0.137$ \\
\hline 14 & 36.889915 & -116.031578 & 090609_14.Spc & $0.562 \pm 0.024$ & $0.286 \pm 0.019$ & $3.753 \pm 0.172$ \\
\hline 15 & 36.889325 & -116.031730 & 090609_15.Spc & $0.88 \pm 0.031$ & $0.796 \pm 0.03$ & $10.497 \pm 0.287$ \\
\hline 16 & 36.889270 & -116.031318 & 090609_16.Spc & $0.56 \pm 0.024$ & $0.169 \pm 0.015$ & $3.055 \pm 0.155$ \\
\hline 17 & 36.889358 & -116.031425 & 090609_17.Spc & $0.544 \pm 0.023$ & $0.179 \pm 0.015$ & $2.828 \pm 0.151$ \\
\hline 18 & 36.889427 & -116.031593 & 090610_18.Spc & $0.591 \pm 0.024$ & $0.183 \pm 0.018$ & $2.949 \pm 0.153$ \\
\hline 19 & 36.889302 & -116.031608 & 090610_19.Spc & $0.613 \pm 0.026$ & $0.295 \pm 0.019$ & $3.993 \pm 0.178$ \\
\hline 20 & 36.889242 & -116.031883 & 090610_20.Spc & $0.849 \pm 0.03$ & $0.728 \pm 0.028$ & $9.204 \pm 0.267$ \\
\hline 21 & 36.889763 & -116.031685 & 090610_21.Spc & $0.907 \pm 0.032$ & $0.79 \pm 0.029$ & $10.277 \pm 0.282$ \\
\hline 22 & 36.888828 & -116.033363 & 090610_22.Spc & $0.758 \pm 0.029$ & $0.644 \pm 0.027$ & $9.573 \pm 0.269$ \\
\hline 23 & 36.889758 & -116.030723 & 090610_23.Spc & $0.769 \pm 0.029$ & $0.674 \pm 0.027$ & $8.534 \pm 0.257$ \\
\hline 24 & 36.889240 & -116.030800 & 090610_24.Spc & $0.51 \pm 0.023$ & $0.196 \pm 0.017$ & $2.89 \pm 0.152$ \\
\hline 25 & 36.889755 & -116.030708 & 090610_25.Spc & $0.573 \pm 0.024$ & $0.299 \pm 0.019$ & $4.61 \pm 0.191$ \\
\hline 26 & 36.889802 & -116.030937 & 090610_26.Spc & $1.057 \pm 0.036$ & $1.181 \pm 0.037$ & $16.045 \pm 0.354$ \\
\hline 27 & 36.890980 & -116.030738 & 090610_27.Spc & $0.519 \pm 0.023$ & $0.138 \pm 0.016$ & $2.341 \pm 0.138$ \\
\hline 28 & 36.891708 & -116.030510 & 090610_28.Spc & $1.018 \pm 0.035$ & $1.171 \pm 0.036$ & $15.556 \pm 0.348$ \\
\hline 29 & 36.891250 & -116.031463 & 090610_29.Spc & $1.084 \pm 0.035$ & $1.316 \pm 0.038$ & $16.405 \pm 0.356$ \\
\hline 30 & 36.890263 & -116.031693 & 090610_30.Spc & $1.083 \pm 0.035$ & $1.191 \pm 0.036$ & $15.627 \pm 0.351$ \\
\hline 31 & 36.889385 & -116.031845 & 090610_31.Spc & $1.033 \pm 0.035$ & $1.156 \pm 0.036$ & $14.831 \pm 0.34$ \\
\hline 32 & 36.888992 & -116.031105 & 090610_32.Spc & $0.645 \pm 0.028$ & $0.692 \pm 0.028$ & $9.216 \pm 0.266$ \\
\hline 33 & 36.889587 & -116.030572 & 090610_33.Spc & $1.024 \pm 0.035$ & $1.175 \pm 0.036$ & $14.963 \pm 0.343$ \\
\hline 34 & 36.890442 & -116.030510 & 090610_34.Spc & $1.001 \pm 0.034$ & $1.109 \pm 0.035$ & $14.617 \pm 0.338$ \\
\hline 35 & 36.891407 & -116.030320 & 090610_35.Spc & $0.881 \pm 0.032$ & $0.891 \pm 0.032$ & $12.024 \pm 0.307$ \\
\hline
\end{tabular}




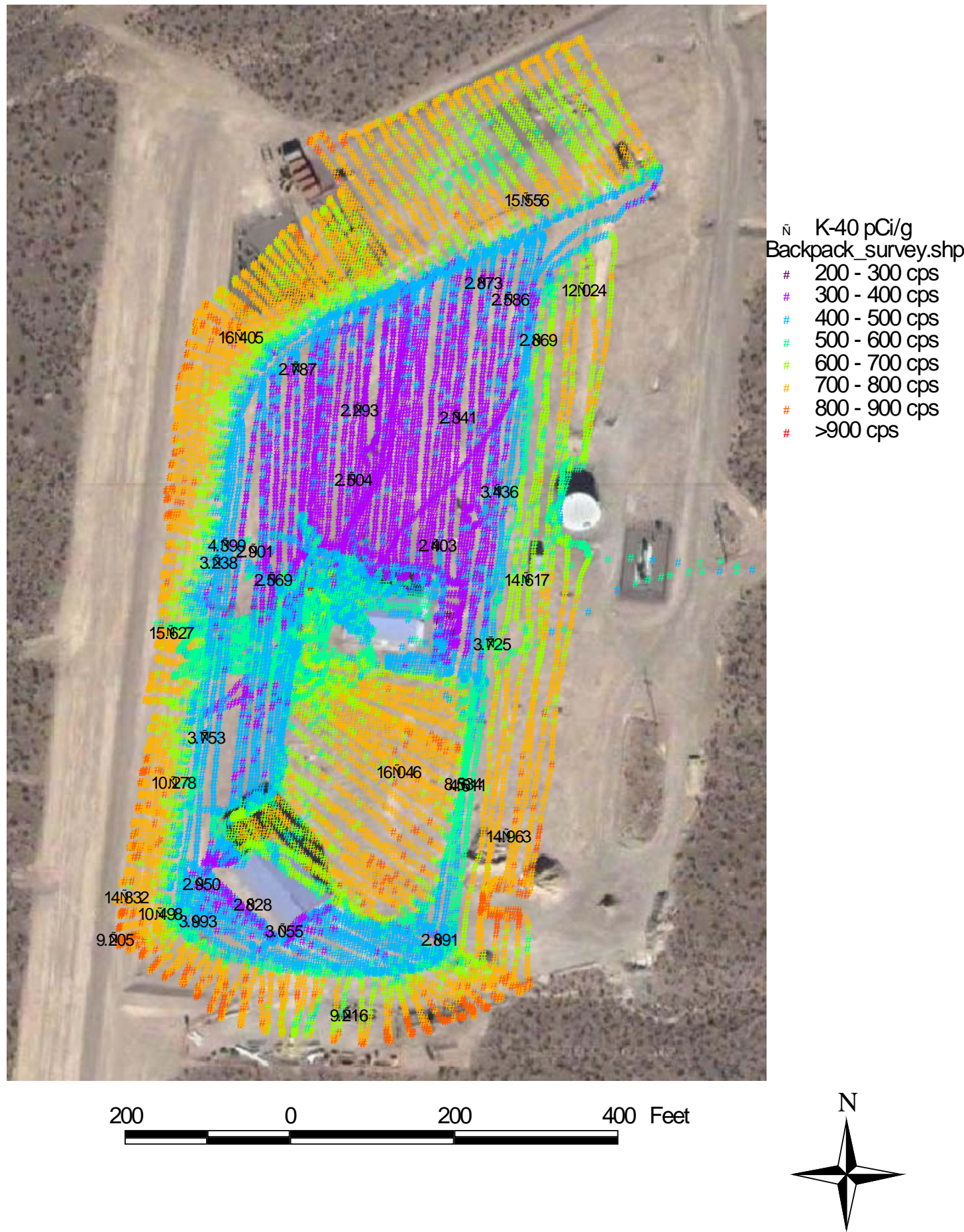

Figure 6: The results of the analysis of the HPGe spectra for ${ }^{40} \mathrm{~K}$ activity in the ground are shown on top of the backpack survey. The measurements inside the Active Interrogation Building were excluded. 


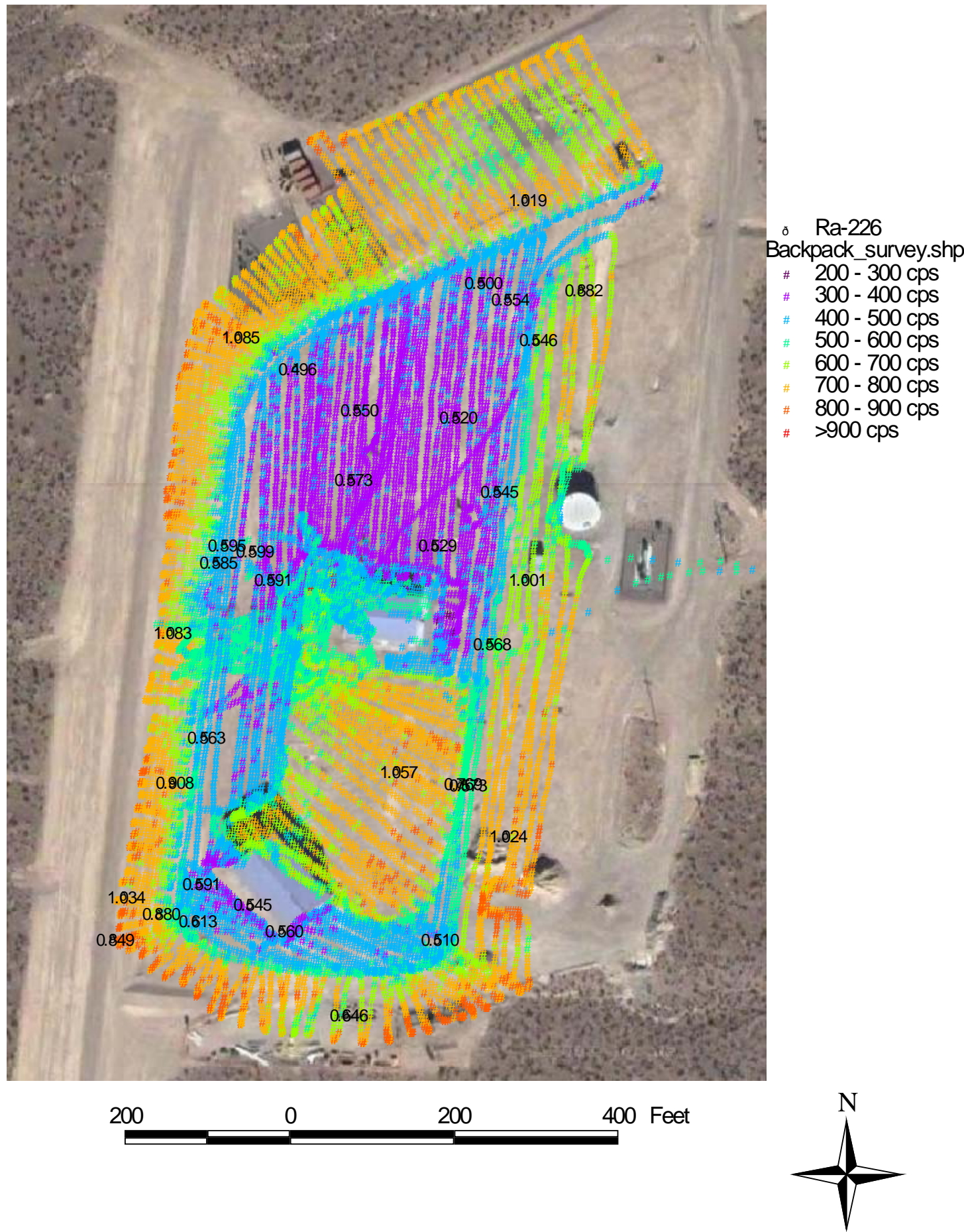

Figure 7: The results of the analysis of the HPGe spectra for ${ }^{226}$ Ra activity in the ground are shown on top of the backpack survey. The measurements inside the Active Interrogation Building were excluded. 


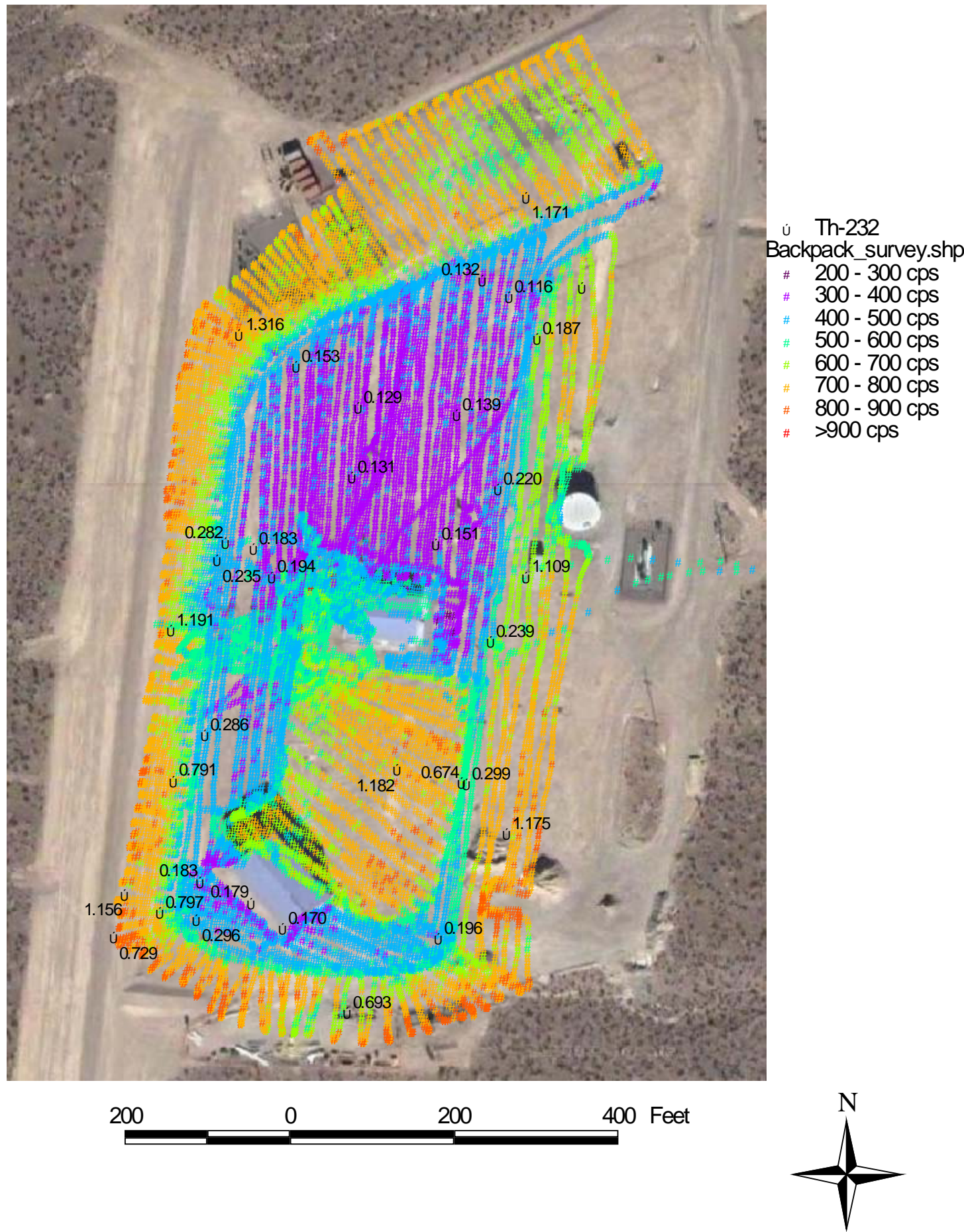

Figure 8: The results of the analysis of the HPGe spectra for ${ }^{232}$ Th activity in the ground are shown on top of the backpack survey. The measurements inside the Active Interrogation Building were excluded. 